\title{
加强中苏科学合作为促进科学事業 的大躍进而战斗
}

一訪苏科学枝术代表团总結报告(摘要)

\section{郭 沫 若}

中国訪苏科学技术代表团汸問苏联的期間正是十 月社会主义革命 40 年紀急的前后, 苏联两顆人 造 地 球衛星上天，毛主席嗢問苏联，六十四个国家的共产 党和工人党在莫斯科开会, 十二个新会主义国家的共 产党和工人党弡表了联合声明, 六十四个国家的共产 党和工人党嶛表了和平宣言。国际局势的發展, 誠如 毛主席所說: 是东風压倒了西風。在国內, 反右派的 斗争获得全面胜利。整風运动展开了大鸣大放大孚大 赔的批評和自我批評, 在全国氾围內促进着工作方法 的改进。工农業生产因而逐步形成高潮, 全国人民都 在鼓起干劲、力爭上游, 以乘風破浪的革命步伐, 实 行工作的大躍进。我們代表团正是在这种形势之下受 着鼓舞，并涩着信心进行工作的。代表团在苏商談、 参覌和祅問, 經过了三个月, 取得重大的收获, 胜利 地完成了我国政府交給我們的任务。

1958 年 1 月 18 日签桎了中苏两国共闰进行和苏 联帮助中国进行重大科学技术研究的协定。两国科学 院在 1957 年 12 月 7 日也签訂了合作协議。两国高等 部和两国农業科学院之間的科学研究工作合作协 議則是和两国政府間的协定同时签訂的。

現在我想談一談关于代表团这一次所签訂的协定 的主要內容。

今年1月18日签訂的中苏两国政府关于共同 进 行和苏联帮助中国进行重大科学技术研究的协定, 是 有重大意义的。它为我国在第二个五年計划期閆科学 技术研究工作的大躍进, 准备了重要的国际合作条 件。协定的主要內容是总結了分年来中苏两国在科学 研究方面合作的經驗, 把第二个五年計划期間必須和 苏联合作或者由苏联援助进行的关键問題都着重地提 出了。这些安排对于第三:个五年計划期間的科学技术 研究工作，也黛下了良好的基础。

协定的第一个主要內容是更有計划有重点地和苏 联进行科学研究的全面合作。122項重大科学技术研 究項目的签訂就表示着这一方面的用意。中苏两国在 科学技术研究的合作方面, 过去八年開作了不少工作,
成績是很大的。苏联对中国已程有了許多的帮助, 例 如我国發展科学技术的十二年远景見划就是在苏联科 学家和专家的协助之下拟訂的。为了实現规划, 在科 学技术研究的合作方面也要象工業建设的合作那样有 計划、有重点地进行，我們才能够员正:地迎㳄赶上:。 因此，在这一次的协商和协定的签江上，由唡国政低 对今后五年的科学研究合作在重点項目上进行了全面i 的安排, 而同时在两国科学院、两国高等教育部、两 国农業科学院之閒也分別签訂了合作协議，将来在两 国医学科学院之間也准备这样做, 以保㖶实現政府协 定所見定的重大任务; 这就使两国在科学技术研究方 面的合作走上了新的阶段。这样重大的工作在㧴们是 第一次进行的, 經驗不够, 而且科学技术研究本身也 在不断变化和發展, 122 項的內容不能說是考虑得十 分周密的, 在每年安排年度計划时, 还必須根据实践 的經驗和新的情况加以必要和可能的补尤和修正。

协定的第二个主要內容是巩固和登展了两国科学 机构和科学研究机构之䦦的直接联系。科学技术研究 的国际合作芭含有外交工作和对外貿易工作的成分, 在一定的范围內必須遵守外交程序和外算少驟, 但是 它有它自己的特点。这主贸是由于科学研究有它的专 門性、复杂性、多变性和时閒上的急迫性。肉此, 在 必要的外交程序和外留步䮡的一定先約下促进两国科 学机构和科学研究机构之閏的直接联系, 牛把这种遖 接联系作为合作的主要形式, 是完奈必要的。关于科 学机构之閒的直接联系, 中苏科学技术合作委員会在: 1956 年已作了原則性的决定，抹在买践中收到了一 定的效果。但經过这一次协定和两国科学院、两国高 等教育部、两国农業科学院之閏的科学技术研究工作 的合作协議的签打, 把这种直接联系进一步加䖪和扩 大了。

在这里还有一点必須指低的是, 这次的协定肯定 了另一种形式的直接联系, 那就是以 122 項蚶的每-一。 項目为中心的㨁接联系。中苏双方对于等 都有一个負步单位, 在直接联系的职权范围內, 可以 
直接商量和决定有关的問題。每一个合作項目的年度 竍划, 也由各該項目的負責单位直接商訂, 紸过双方 有关領导机关批准后即可㷋生效力。这种形式的直接 联系的另一个特点是加强了双方的协調工作。因为 122 項中的人多数項目双方都是由几个单位参加执 行 的, 負責单位对于这些参加单位負有协調的貢任, 这 就可以达到集中双方力量解决主要問題的目的。但 是, 两者是相悑相成的, 第二种直接联采的形式抹不 代替第一种的直接联系。

协定的第三个主要內容是两国科学家的来往肯定 了以采取短期学术出差为主的方式。在第一个五年計 划期間，我棩曾桱大批地比較长期地聘請苏联专家来 帮助我国的建設工作，这是非常必要而且成效卓著 的。这样聘請的专家在第二个五年計划期間虽然还是 有大量的需要，但会比較少一些了。在第二个五年計 划期間，为了完成科学技术战綫上的巨大任务，我們 必須在苏联高級的科学家和专家的援助下生长自己的 科学技术力量, 逐步作到能够独立解决国民經济建設 中所提出的科学技术問題。但是高級的科学家和专家 在苏联都担负着重入的建設共产主义的任务, 誶他們 长期腳离自己的南位, 在他們是不可能, 在我椚也不 泣該。因此, 我們这一次和苏联商定了采用“学术出 差” 的方式, 就是在我国科学技术研究工作中的确需 要苏联科学家来华帮助抖在有了光分准备的条件下, 請苏联科学家短期出差到中国来指导工作。中国去苏 联的专家也采取同样的方式，但中国去的㻦竟少，而 苏联来的畢竟多，在这里特别表示出了苏联对于我們 的又一次的罡私的帮助。

协定的第四个主要內容是解决了关于非商品的科 学設备、器械、仪器、样品、材料、試剂以及小量零 星器材的供应问題。科学研究所需用的設备、仪器等 物質条件, 在原則上我阿是应当采取自力更生的方 針, 鼓励工厂、髞等学校和研究机构自己制造的。在 第二个五年計划期閣, 工業会有更进一步的發展, 勤 佮办科学的方部也会进一步得到实践, 这一方面的自 給程度是会比主去八年有所改善的。但是, 由于我国 技术上的落后, 国际援助的需要仍然会是大量的而且, 迫切的。在我国所处的国际条件下，这方面的主要支 援是来自苏联。但是, 經过对外貿易途径只能解决大 宗的商品和物質供应, 对于非商品和小量需星物質的 供应閣題, 江去八年一直汥有找到解决的办法。在科 学研究工作中, 这一方面的需要却是大量的、迫切 的, 往往由于一、克的化学試剂或者其它小量器材的 缺乏而使工作长期陷于停頓。因此, 在协定中就把这 一問題列为一条, 由双方政府各授权一个适当机构:

“目责供应为进行科学研究工作所必需的, 两国 普通
进、出口商品中所未包括的設备、器械、仪器、样品、 材料和武剂, 以及其它小量害星器材。”

协定的第五个主要內容是监督执行問題。这个以 122 个重人科学技术合作項目为中心的两国政府間的 协定的签汀，是中苏两国閶一个重要的科学技术合作 事件。它不是两烈政府之開的某一个部䅀的事情, 而 是哖涉到双方的許多部門。从項目的內容来看, 有科 学技术研究方向、实驗方法、科学家来往、資料交換 和物質供应等复杂問題。这些項目的变化性鄚很火, 不仅在五年中会有很人的变化, 就是在年度計划确定 了以后也还会有变化。当然, 其中有許多問題郘应当 由有关单位的直接联系解决，但是也有許多重大問 題, 特別是調动各方面的力基問題, 双方政府如不投 权一个总的监督和协調机构, 就很难順暢解决。所以 协定中有了这样的規定: 中国方面以中国国务院科学 規划委員会，苏联方面以苏联部长会議国家科学技术 委員会为双方的总的监督和协調机构。

至于协定执行中有关重臬科学技术資料的轉交, 专家的派遗和接受, 协定更明确規定了由中苏科学技 术合作委員会来担負这方面的任务。

代表团在努力完成上述主要任务之外, 在汸苏期 間还注意了另一个重䍂問題——学習苏联發展科学事 業的基本經驗。在訪苏期間, 代表团的成且亲身体会 到苏联科学的高度水本。在政治上和經济上苏联的酷 会主义制度比資本主义制度优越, 許多人是早已㑑服 的, 但是在科学技术上苏联已經处于世界上最先进的 地位, 特別是在許多重要科学技术部門苏联比美国还 要先进, 在我国科学界中扭不是沒有人怀疑。現在我 們科学家們大都一致公認: 苏联所已經达到的成就和 我們所知道的苏联的成就, 中間有很人的距离。苏联 是作得多說得少, 資本主义国家是說得多作得少。例 如人造地球衛星和洲际导弹的成功就是最显著的例 証。这些科学技术上的伟大成就都是一系列的科学和 技术相应郋展的結果, 包括着嗢气技术、高滥合金、 自动控制、空气动力学、無䋐电、精泌机械、牛导体、

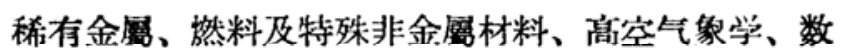
学和計算技术、生物学等的互相配合。当然, 在核子 物理和原子能利用方面, 苏联也是站在世界最前列 的。这一閏科学的發展也和超純材料、特殊合金、放 射化学、化工和动力技术、白动化、放射生物学、放 射医学等学科的费展分不开来。对于苏联之所以能在 很短的时期內获得如此伟入的成颜, 代表团成員各人 的体会虽然不完全相同，但在基本問題上的看法大体 上是一致的。苏联是第一个社会主义制度的国家, 由 于酒上会主义制度的优越性，四士年来在苏联共产党的 
颃导下，以馬列主义为指导思想，一切事業都在咨飞 科学研究工作也是在党的領导下进行的。一切 科学技术的研究工作必須为社会主义建設服务, 必須 根据国家建设的需要有計划地进行。广大的科学工作 者四十年来已受到不断的敉养和鉔炼, 大都具有坚定 的共产主义人生覌, 有高度的集体主义精种和自喾的 紀律性, 全心全意为人民服务, 为融会主义事業服 务。这就使科学發展不断地躍进, 在短时期內赶上了 最先进的世界水午。这一条是我們共同体会到的最基 本的經驗。

在这样的認識之下进一步具体研究, 我門覚得有 以下八点値得鯰眞地学㕷:

第一、理論和实际的結合。这虽然是一个尽人皆 知的馬列主义的基本原理，但在实际工作中却不是任 何地方都解决得很透徽的。苏联科学界光滿着理論結 合实际的風气, 無論是基础科学还是应用科学的研究 大都有明确的目的性，为国民經济建设或者国防建设 服务。不仅研究技术的人要注意經济問題, 研究理論 的人也要注意实現这些理論的技术和經济問題。不仅 工程师們对絓济建设和国防建设上的一些問題非常熟 悉, 科学研究机构的科学家和高等学校的教授們对于 有关厂矿的各种情况, 如生产指标等, 也火都非常熟 悉。“为科学而科学”的研究作風在苏联是被認为不光 荣的, 緅常受到批判。我們的科学家和教授們熟悉生 产情况的人是比較少的, 研究基础科学的人在这方面 的缺点特別突出。我們大家鄚認为在这一方面应該認 美地补課。

第二、重点梫展, 全面安排。苏联科学今天的陣 容是很雄厚的, 各个方面都相当充实。从苏联科学事 業的历史郋展来看, 目前發展最快、成效最大的科学 部門都是根据重点郋展的方跍唚展起来的。苏联在社 会主义建设中对于㖟展科学給以了極大的注意。由于 科学技术研究工作的氾围無边無际, 而人力物力总是 有一定的限度, 因此在一定时期內, 必須围繞某些和 济济建設、国防建设关系重大的科学部門进行研究, 使这一些重点部門在比較短的时期內以最高的速度向 前迈进。同时以这些部門为骨干来带动其它有关的科 学部門, 从而促进一般科学水平的提高。这样, 重点 㻐展扞不是坬立的㻐展, 而是围繞着一定重点对有关 的科学部門作全面安排。苏联科学界的一些負責同志 对这一点十分强調, 認为平均主义的登展是有害的。 在这一方面苏联进行过不少的斗爭。

第三、科学研究的計划性和协調工作。在䣥会主 义制度下, 任何工作都是有計划地进行的, 科学工作 当然不能例外。苏联全国約有 3,000 个科学机构, 有 24 万科学研究人員, 研究面非常广閤。要使整个研究
工作納入計划性的栜道，在有細致的分工之外，尤必 須有严密的合作。苏联目前最有成效的科学研究部門 也就是計划性最强、协調工作最有成績的部門。苏联 領导方面目前对于科学事業正在加紧全国性的計划工 作和协調工作，我們可以預見苏联科学界的婎厚力量 必将更进一步得到發掩, 做出更有光㷈的成就。

第四、大力解决科学干部問題。近代的科学活动 如果不能形成一个雄厚的战斗部队, 是不可能解决任 何巨大的国家任务的。苏联培养科学干部的最基本措 施当然是实施了社会主义的教育制度，对学生的政治 質量給予以足够的注意之外，一般是选择成䊀最优秀 的学生从事科学研究。40年来, 苏联培养出了 380 万受 过高等教育的专阿人才，其中有 100 万工程师。在这 个基础上形成了 24 万人的科学部队。作为 24 万人的 科学部队的領导骨干有一万多人, 中閒骨于将近十万 人。苏联培养这些骨干的办法, 有三点值得特别注意。

(1) 对于一些重要、急需而又空白或薄弱的部 門，首先从相近的学科动員一些政治和業务都好的科 学家轉業, 以开辟这些新的科学部門。不这样, 是不 可能把这些部門迅速發展起来的。苏联原子能的研究 和生产方面的許多高級骨干都是过去轉業而来的。

(2) 研究生制度在苏联是成效卓济的。研究生 制度的基本特点是在严格的要求下，按照周㳣的計 划，在各方面給以較好的条件，在三、叫年的比較短。 的时期內, 对具有相当科学水平的青年进 行 基本 訓 鄱, 使他們掌握某一閒科学研究的最基本的資料、研 究方法和进行实驗的技术, 这要比在职培养快得多。

(3) 对于最急需的科学部門的斗部, 还有一种 特殊的培养办法, 即选拔中学畢業生中各方面都是最 优秀的学生, 在較短的时期內, 在紧张而严格的数学棓十 划和光分的物質没备的条件下学管最重要的专門知識 和技术。这种办法的效果在目前看来也是十分显荠的。

第五、学和科学研究相結合。苏联的高等学校 中, 数学和科学研究一般結合得很好, 高等学校教师一 般都同时在进行科学研究, 科学研究机构中的科学家 一・般也策学任务。数学和科学研究是相輔相成的。 数师不作科学研究, 决不可能提高教学質量, 科学家 不策教学工作, 就很难有效地培养和选拔青年科学干 部, 也不可能从富有想象力的学生中吸取㓣造性的啓 示。我国有些人認为教学和科学研究相矛盾的說法, 他們很不了解, 認为不应該存在这样的問題。

第六、提倡学术界的自由爭論。苏联科学界对于 不同学派的态度是很正确的。任何学科都可能有各种 不同的方向和途径，凡是認员为㖣会主义事業服务、 进行科学研究的学者, 不管他的見解和方法如何, 在 苏联都受到杽重。不同的或者相反的意見尽可以展开 
自由爭論。这种風气十分有利于科学家的大胆刢造。 虽然在个别問題上, 苏联科学界也腾生过以宗派态度 对付学派的事件, 但是这种作法受到了苏联党和政府 的批評。

第七、勤佮办科学。苏联科学界的艰苦奋斗精融 給我們的印象也很深刻。苏联政府对于科学的陊展, 特別是重点發展, 不惜大量的人力物力的投資, 在科 学研究的没备和仪器方面也不断鞛新, 采取最新技 术, 但苏联的科学家和呚授們却大都很节約地在利用 他們旧有的房屋, 而且也利用老的設备和仪器作出許 多新的成果, 培养出許多优秀的青年干部。更重要的 是, 对于科学实驗基地的建立, 設备、仪器的管理, 苏联积照了許多好的經驗, 建立起适当的制度。如全 苏科学院有专門机构来为科学研究机构进行基本建设 的设計, 这样就可以避免浪費, 提高質量。在仪器供 应方面也有很好的管理制度, 全苏科学院有仪器供应 中心統一管理和調配科学院各个研究所、考察队（包 括远征南極的考察队) 的設备和仪器, 各单位的需要 計划在得到批准后, 即由这个供应中心按計划供应; 对于各单位不再需用的設备、仪器, 便由供应中心調 配給其他单位使用，有損坏的由供应中心負責修理; 对于一些貴重的仪器, 則布置若干据点以供有关单位 共同使用。他們在不断地防止和反对各单位的各搞一 套、各自为政的本位主义現象。苏联科学界的領导方 面認为他們这一方面的工作还有許多缺点, 还沒有能 够充分發揮設备和仪器的作用, 浪費現象还很严重。 他們正在考虑一些新的措施来改善这方面的情况。

第八、重視科学情报工作。苏联有規模宏大的科 学情报机构, 专职工作人員 4,000 余人, 連同争职的 共有一万余人。各个科学研究机构也都非常重親科学 情报工作。沒有良好的国內、外的科学情报工作, 科 学研究工作的計划就沒有可靠的基础, 就必然产生直 目性, 一方面会造成許多重复泿費現象, 另一方面会 由于不了解有关的新的进展, 而失去許多学替参考的 机会, 这所造成的損失更是难以計算的。因此, 在科 学情报工作上多用一些必要的人力物力, 表面看来也 許太多了, 实际上是一个很大的节約。

上面八点是我們初步体会到的苏联科学工作的一 些成功的經驗, 由于时間有限, 覌察未能普迶和深 入, 要全面地总結苏联科学工作的基本經驗, 在我們 是不可能的。当然, 仅就上迅的这八項成功的經驗来 說, 也不能說苏联所有的科学机构都完全达到了同样 的水平，錯語的思想和不合理的現象也还是存在的。 但后者不是苏联科学工作中的主流。我們应当学㚙苏 联的先进經驗, 对于苏联科学界所反对的一些不良現 象則应当引以为龟籢。
根据这次中苏两国科学合作談判和参䙺勒問的体 会, 我門有下列的几点具体建議:

一、广泛梁入地宣传和介紹苏联科学技术的成颜 和先进經驗以及中苏两国政府关于共同进行和苏联帮 助中国进行重入科学技术研究的协定的主要內容。要 使这一次代表团訪問的收获成为动員我国科学界开展 大躍进的一个大的推动力量。代表团的团員們和䫏問 們以及工作同志們还应当就自己的心得对全国的科学 技术界进行書面的或者口头的传达。我們建議全国自 然科学专門学会联合会和全国科学普及协会能够担負 起組織这一次大規模宣传的任务。我們代表团的全体 同志当热烈地参加这一工作。

二、两国政府的协定所規定的合作項目必須認道 地执行。苏联方面已經作了充分的准备。我方的有关 部門必須認㬊地检查我們的准备工作。凡是准备不切 实的应該加强, 准备实在来不及的可以按协定所規定 的程序向苏联有关方面提出修改項目的內容。無論如 何不能白白派貿苏联科学家的时間。当然另一方面, 我們也必須預見到: 这样一个大規模的科学研究的国 际合作是一个新工作的开始, 在执行过程中一定会遇 到一些困难, 工作上也可能有一些缺点, 我們应該不 断地总結經驗, 改进工作, 提高效弯。

三、在我国第二个五年計划期內，在科学技术的 研究上应該坚决柇取以結合中国实际、㓣造性地掌握 和运用苏联先进成就为主的方針，同时还要注意發揚 我国的科学遺产，总結我国工农業生产中的群 众桱 驗。我們認为这是我国科学工作中的多、快、好、省 的方飫的一个重要方面。裂使我国的科学能在不太长 的时開內赶上和接近世界先进水平，必須使我們这一 代的科学工作者, 不論是高級的、中級的和初級的, 都要大量掌捯苏联等兄弟国家先进的科学成就, 和利 用这些成就来培养青年, 㓣造性地把它們应用到促进 我国工农業狆展的工作中去。为了很好的掌握苏联和 其它国家的科学成就, 必須加强我国的科学情 报机 构, 各科学研究机构也要加强科学情报工作, 掌握情 报, 扭研究如何充分地加以利用。

四、科学进軍的最中心的环节是科学干部的問 題。在科学干部的使用和培养方面，八年来是有巨大 成績的, 但和我們国家的需要还相差很远, 科学干部 的發展还钢乏計划性。我們希望在1958年內, 把今后 十年关于科学干部的使用和培养的嫢划制倍出来。現 有的老科学家如何深入.思想改造和發揮潜在力量, 青 年科学干部如何培养, 都应該有一定的計划。要考虑 到各种不同专業的分配, 更要考虑政治条件的具备, 要使科学工作者都成为紅色的专家。研究生制度, 苏 联是行之有效的, 我們应当根据我国的具体条件研究 
如何运用这个制度。对于派到苏联和其他国家的留学 生、研究生、实睗生和进修人員, 在专業的配备上, 在学㕷的办法和制度上, 都应当总結过去的經驗, 肯 定成績, 改正目前还存在着的各种缺点。如果关于科 学干部的見划不能紧跟着㥅展科学技术的远景規划制 定出来, 在第三个五年計划期末我門的科学要迁上世 界先进水本是汥有保部的。

闹志門，自从去年国务院科学䙺划委員会第四次 扩大会議以来, 到今天时閒相隔只有八个月, 但在这 期閒制过反右泥斗争和整風运动，我国整个政治形势 理生了深刻的变化: 广大群众的什会主义积極性进一 步得到了發掦，全国氾围內展开了工农業生产人躍进 的运动。就科学界来說, 广大科学工作者的社会主义 党语比以前也大大地提高了。科学界的右派分子被清 查了出来, 餈产阶釉右派分子的反社会主义科学網領 被粉碎了，右派分子在群众中徹底坬立了，他們的陰 蹀徽底破了产; 我們在科学工作中的吘多缺点和問 䫖，也充分地暴露了出来，正在有效地改正和解决。 最近一个时期各地程烈烈的反浪費、反保守、比先 进、比干劲的运动，以及在科学界展开的資本主义和社 会主义两条道路和多块好省和少慢差費两种方法的大 䜅論, 对科学工作同样起着巨大的促进作用。科学工 作者提出了自我改造的但議, 将推动科学界的整風运
动走向新的高胀。可以預計，在政治战綫、思想战綏 上塥会主义革命基本胜利之后，一定会有科学技术上 的革命高潮到来。我国科学界应当和工农業生产的人 躍进相配合, 努力从事科学研究和科学曹及工作。

毛主席說, 当前劳动人民的生产热情就像源子核 被冲破了一样。这个比喻是牦恰当也汥有的。原子核 被冲破会引起連鎖反应的現像, 因而在交数建没和政 治工作各方面都引起了热潮的高涨。在这样的情势之 下，我們科学家是絕对不能作壁上覌的。我师必須在 科学事業上也严格满守多、快、好、省的方部, 努力 成为促进派, 而不是成为促退派。工农業生产热情的 全面高潑，几亿人民在勇猛地向人自然进策，在这里 我国的科学家和技术家便成为我国人民向人自然进年 的技术指导和技术骨干。这是光荣而烺巨的任务, 我 們必須以乘風破浪的气概来完成这項任务。我鬥一方 面要提高，一方面要普及，要在普及的:基础，上提高， 在提高的指导下普及。

同志們，情势对于我們是十分有利的，科学發啨 大躍进的客覌条件已經充分具备了，主要就在期待着 我們的主覌努力。請謨我們跂起干劲、力爭.上游, 为 爭取提前实現十二年科学規划所見定的任务, 为金面 支援工农業生产的大躍进井促进科学事業的人踓进， 不届不挠地北闹战斗。

\section{科学为生产躍进再躍进 一記国务院科学規划委員会第五次会議}

3 月 5-12日在北京举行的国务院科学規划委員 会第.五次会議, 向全国科学技术界提出了一个光荣的 战斗任务: 科学必須为生产大躍进服务。

这次会議是在全国生产大躍进，全民整風运动的 深入开展的新形势下召开的; 会議的各項議程都渗透 着大躍进和整風的精神。会議听取和討論了中国訪苏 科学技术代表团的总結报告和去年科学工作成績的报 告, 討論判目原則上通过了今年的自然科学技术研究 計划、哲学社会科学长远規划雨要草案和科学規划委 員会掌握的今年重点研究項目; 討論了进一步改善科 学研究工作条件問題和建立全国科学情报中心問題; 听取了中共中央宣传部副部长、中国科学浣副浣长陈 伯达关于哲学社会科学如何躍进的报告, 以及科学規 划委員会委員和各有关单位、各地代表共 25 人的發 自。会上宜布了国务院关于撤銷右派分子曾炤揄、錢 伟长、鐵端升、陈达、费孝通、李宗恩、袁翰青、周
慧明八人科学規划委員会委員职务的决定。

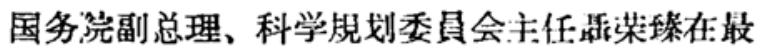
后一天的会議上作了总結㡎言。他指比：科学必須为 生产服务, 这是科学事業的根本方郎。現在是生产人 躍进迫切要求科学人躍进的时候。争取我国科学事業 大躍进的最根本的問題是加强科学队伍問題, 而加强 科学队伍的主要方法是整滍。当前的整湟运动, 不仅改 浩了科学工作者, 也大火地改善了党对科学工作的領

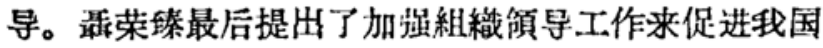
科学事業大躍进的几个問題。他說, 应該注新在生产 中大量培养干部; 要培养担任科学領导工作、經过較 长期革命斗爭鉭炼的老干部，使他們成为通晓某一門 科学知識的专家; 要动員高等学校中的强大科学力量; 要积極开展地方科学技术研究工作。

中国科学浣院长、科学規划委員会副主任部沐若 在会議开始时所作的中国訪苏科学技术代表团总結报 